\title{
OS Impactos da GlobalizaÇÃo na PRESERVAÇÃo doS PATRIMÔNIOS CULTURAis: a festa do divino de Mogi das Cruzes - SP
}

\author{
THE IMPACTS OF GLOBALIZATION ON THE PRESERVATION OF CULTURAL \\ HERITAGE: \\ the holy spirit feast of MOGI das CRUZES - SP
LES IMPACTS DE LA GLOBALISATION SUR LA PRÉSERVATION DU PATRIMOINE CULTUREL:
la Fête de L'esprit Saint de MOGI das CRUZES - SP

\author{
Marcia das Dores Cunha Alves Valim* \\ Francisco Carlos Franco** \\ Rosália Maria Netto Prados ${ }^{* * *}$ \\ Luci Mendes de Melo Bonini ${ }^{* * * *}$
}

\section{RESUMO}

Estuda-se a influência do isolamento geográfico, econômico e cultural na manutenção e na permanência das tradições populares e religiosas e se isso influencia ou influenciou na criação de políticas de salvaguarda e preservação de patrimônios culturais que possam conter os efeitos deletérios do nivelamento cultural no cenário da globalização. Para esta reflexão, utilizou-se um estudo de caso da Festa do Divino Espírito Santo de Mogi das Cruzes e as políticas municipais de preservação do patrimônio histórico local. Entendeu-se que o ser humano tem duas dimensões: a dimensão religiosa que vive em dois planos: sua existência mesma e a esperança da vida transcendental e, neste caso, o tempo sagrado é circular e o ser humano não religioso, que dessacralizou o mundo, relativizando-o cujo tempo é linear. É na visão do tempo cósmico, repetível indefinidamente que o ser humano religioso conseguiu manter as tradições vivas, despertando um olhar mais acurado dos promotores de políticas culturais e de turismo que pudessem, mesmo com interesses capitalistas, buscar conservar, preservar e salvaguardar essas tradições.

Palavras-chave: Tempo Circular. Isolamento Geográfico. Religiosidade.

\section{ABSTRACT}

This study try to understand the influence of geographic, economic and cultural isolation as a cause of the maintenance and permanence of popular and religious traditions, and if it influences or influenced the creation of policies for the safeguarding and preservation of

\footnotetext{
* Mestre em Políticas Públicas pela Universidade de Mogi das Cruzes e Professora da Rede Pública Municipal de São Paulo. E-mail: marcia.valim@yahoo.com.br

** Doutor em Educação pela Pontifícia Universidade Católica de São Paulo. Professor universitário e pesquisador no Mestrado em Políticas Públicas na Universidade de Mogi das Cruzes. E-mail: prof.franfranco@gmail.com

*** Doutora em Semiótica e Linguística Geral pela Universidade de São Paulo. Professora da Faculdade de Tecnologia do Centro Paula Souza, pesquisadora no Mestrado em Políticas Públicas da Universidade de Mogi das Cruzes. E-mail: rosalia.prados@gmail.com

**** Doutora em Semiótica e Linguística Geral pela Pontifícia Universidade Católica de São Paulo. Pesquisadora no Mestrado em Políticas Públicas da Universidade de Mogi das Cruzes, Professora universitária, pesquisadora colaboradora no Instituto de Pesquisas Tecnológicas de São Paulo. Email: lucibonini@gmail.com
} 
cultural heritage that may contain the deleterious effects of cultural leveling in the scenario of globalization. For this reflection, it is presented a case study of the Holy Ghost Feast of of Mogi das Cruzes and the municipal policies of preservation of the local historical patrimony. It was understood that human being has two dimensions: the religious one, living on two steps: his/her very existence and the hope of the transcendental life, so his/her time is sacred and circular and the non-religious individual, who has desacralized the world, relativizing him/her whose time is linear. It is in the vision of cosmic time, which is endlessly repeatable, that religious human being has managed to keep the traditions alive, arousing a more accurate look at the promoters of cultural policies and tourism that could, even with capitalist interests, seek to preserve and to safeguard these traditions.

KEYWORDS: Circular Time. Geographic Isolation. Religiosity.

\section{RESUME}

Il étudie l'influence de l'isolement géographique, économique et culturelle en tant que cause de l'entretien et de la permanence des traditions populaires et religieuses, et cette influence ou influencé la création de politiques de préservation du patrimoine culturel sauvegarde qui peuvent contenir les effets délétères du nivellement culturel dans le scénario de la mondialisation. Pour cette réflexion, nous avons utilisé une étude de la fête du Divin SaintEsprit du Mogi das Cruzes et politiques municipales cas de préserver le patrimoine local. Il compris que l'homme a deux dimensions: l'homme religieux qui vit sur deux plans: leur existence même et l'espérance de vie transcendantale et le temps sacré est l'homme circulaire et non-religieux qui a profané le monde, relativisant dont le temps il est linéaire. Il est la vision du temps cosmique, répétable indéfiniment l'homme religieux a réussi à garder les traditions vivantes, réveillant un peu plus près des promoteurs des politiques culturelles et touristiques qui pourraient, même avec les intérêts capitalistes, cherchent à conserver, préserver et sauvegarder les traditions.

MOTS-CL亡̀S: Temps Circulaire. Isolement Géographique. Religiosité.

\section{INTRODUÇÃO}

Em 2012, por influência do Calendário Maia, a mídia e o cinema aproveitaram para explorar o tema do fim do mundo, era o apocalipse que surgiu nas entrelinhas do Popol Vuh, o livro sagrado do povo que vivera na mesoamérica, entre 1000 anos antes da era cristã e, provavelmente, teria desaparecido em torno de 250 anos depois de Cristo. Outros calendários marcam tempos diferentes: 2016 era o $4.714^{\circ}$ ano do calendário chinês, cujo animal simbólico era o macaco. O ano novo judeu, neste mesmo ano, foi o de número $5 \cdot 777$, são diferentes culturas e diferentes formas de contar o tempo.

A medição do tempo é um instrumento de poder, por este motivo muitos calendários foram alterados por reis e imperadores. Por exemplo, o Calendário Juliano entrou em vigor no dia $1^{\circ}$ de janeiro de 45 a.c. A Igreja controla o calendário que tem raízes no sagrado, como por exemplo: o Concílio de Niceia em 325 transformou o domingo num dia festivo e fixou a Páscoa no primeiro domingo, 
depois da primeira lua cheia da primavera e o calendário Gregoriano de 1582 quebrou a continuidade do tempo em dez dias (LE GOFF, 1982).

Diferentes calendários marcam diferentes tempos históricos na humanidade, e, com certeza, trazem diferentes formas de ver a realidade, a exemplo disso tem-se as tribos que ainda contam o seu tempo de forma cíclica. Diamond (2005) afirma que os diferentes ritmos nos avanços da humanidade se deram graças às diferenças entre os ambientes e não diferenças biológicas, o que conduz ao pensamento anterior, diferentes ambientes, diferentes culturas e diferentes percepções do tempo.

O objetivo deste trabalho é refletir sobre o tempo cíclico que mantém as festas populares presentes mesmo diante do cenário da globalização, entender como essas festas se mantiveram e se mantêm muito próximas de seus aspectos religiosos de origem apesar de emergir, no contexto atual, aspectos turísticos que desabrocharam por conta do mundo que necessita de cadeias produtivas. Deste foco, emergem alguns questionamentos: i) em que medida os diferentes ambientes, a sua geografia, sua economia permitem (ou não) que tradições sejam resguardadas? ii) que exemplos podem ser citados em que o tempo linear e o tempo cíclico se encaixam na manutenção dos patrimônios culturais ligados às festas religiosas? iii) como pensar em políticas de salvaguarda e preservação de patrimônio cultural que possam deter os efeitos deletérios do nivelamento cultural no cenário da globalização?

Este texto busca responder a todos os questionamentos de modo breve e delineia alguns caminhos que podem conduzir à compreensão de o porquê algumas culturas mantêm preservadas suas tradições.

Não é fácil a tarefa de comprimir em poucas páginas todas essas respostas, por isso serão seletivos os apontamentos que lancem alguma luz sobre essas questões, a fim de que o debate sobre as políticas culturais olhe mais atentamente para essas questões.

Ao se responder a essas questões, pretende-se compreender porque o fenômeno Festas do Divino pelo Brasil se mantém e mais detidamente, refletir sobre a permanência de mais de 400 anos da devoção ao Espírito Santo no município de Mogi das Cruzes. Assim como outras festas, ela movimenta turistas ao longo dos dias de intensos festejos, num cronograma bastante rico de eventos folclóricos e religiosos, tais como missas, alvoradas, novenas, encontro de folias, folguedos 
infantis, quermesse, procissão, e a célebre Entrada dos Palmitos, uma procissão de caráter folclórico religioso que lembra as festas pagãs da fertilidade.

A preservação do patrimônio é muito importante, pois o patrimônio local possui significado simbólico para comunidade, é ele que auxilia as pessoas de um determinado território a entrar em sintonia com a sua identidade com o sentimento de pertencimento.

\section{A SUPERPOSIÇÃO DOS DIFERENTES TEMPOS HISTÓRICOS NA PAISAGEM URBANA: A PERMANÊNCIA DOS PATRIMÔNIOS HISTÓRICOS}

O processo de globalização tem impulsionado o desenvolvimento das forças produtivas sociais. Motor da civilização ocidental, a globalização conduziu muitos países e regiões para o desenvolvimento, para desfrutar da civilização, da ciência e tecnologia ocidentais, por um lado, e por outro as comunidades locais foram confrontadas com a perda das características culturais locais, bem como o risco de a cultura local desaparecer.

O avanço do progresso, que evidencia a "evolução" das civilizações no tempo linear, sufoca a paisagem urbana, destrói pedaços materiais e provoca o apagamento de práticas que já não servem para o novo modelo que emergiu no cenário neoliberal. Mas muitas coisas que permanecem no silêncio do burburinho do dia a dia, como as festas religiosas, por exemplo, irrompem e ocupam os espaços da cidade quando o tempo cíclico se avizinha.

Para Le Goff (1982), foram os filósofos estoicos que difundiram a teoria dos ciclos a de uma idade de ouro seguida de uma idade decadente. Religiões e culturas que se espalham, novas ou velhas acreditam num novo tempo, na vinda de alguém que virá redimir a todos, um projeto salvacionista que representa o benévolo final dos tempos. Enquanto este tempo não vem, os rituais o anunciam. No cristianismo a frase lapidar para que se espere esse tempo é: “Ele partiu o pão e deu aos seus discípulos dizendo: Fazei isso em memória de mim"! A cada vez que este ritual se renova, se renovam, também, as promessas da salvação. 
Claval (2014) destaca que as festas são uma marca de ruptura com os dias comuns, em especial as que marcam os tempos com a vida coletiva, religiosa ou cívica de uma comunidade, que geralmente são organizadas em datas e espaços fixos que consistem em momentos relevantes da vida da cidade. Assim, por meio das danças, procissões, músicas etc., as festas possibilitam que "Cada um é ao mesmo tempo ator e espectador, e vive um momento de intensa emoção, comunhão e evasão. $\mathrm{O}$ sentimento de pertencimento coletivo e, então, muito forte”. (CLAVAL, 2014, p. 139).

Assim são as festas, renovação de promessas para que se avivem na memória dos participantes as promessas da idade de ouro, do tempo de salvação é o tempo sagrado, intervalos em que parte da idade de ouro subjaz na imaginação do povo. É o corte no tempo linear e no tempo biológico: não há morte, há cura, não há trabalho: é feriado. O Tempo sagrado (ELIADE, 2001) é circular, reversível, presente mítico que num certo aspecto se compara à eternidade.

O calendário cíclico dos Brâmanes é de 435.00o anos, o que corresponde a um dia de Brahma, e no final deste dia a Terra é destruída, para depois recomeçar depois de um outro tempo enorme, e assim continua Le Goff (1982) afirmando que também os chineses viam o ciclo do mundo de 129.600 anos e que o mundo existe apenas como possibilidade num outro período igual a este.

O desespero da curta existência humana, a consciência de sua finitude do corpo físico cria um tempo sagrado: um pequeno tempo, dentro do grande tempo, sempre cíclico.

Para Corrêa (2008), o ato de festejar se confunde com a história local de um determinado grupo, e faz emergir um sentimento de pertencimento por meio de ações materiais e imateriais, as quais denotam o poder sobre o espaço da festa e de todos que dela participam.

Assim temos o tempo linear, o da vida e dos sistemas produtivos e consumistas que têm início, meio, obsolescência e fim, mas temos também o tempo cíclico, que transborda nos momentos sagrados em que os homens buscam a salvação, a idade áurea. Isto posto, surge então o primeiro questionamento deste percurso: i) em que medida os diferentes ambientes, a sua geografia, sua economia permitem (ou não) que tradições sejam resguardadas? 
Para Santos (1988, p. 23):

A paisagem não se cria de uma só vez, mas por acréscimos, substituições; a lógica pela qual se fez um objeto no passado era a lógica da produção daquele momento. Uma paisagem é uma escrita sobre a outra, é um conjunto de objetos que têm idades diferentes, é uma herança de muitos diferentes momentos. (...) A cidade é essa heterogeneidade de formas, mas subordinada a um movimento global. O que se chama desordem é apenas a ordem do possível, já que nada é desordenado. (...) Assim, a paisagem é uma herança de muitos momentos, já passados, o que levou Lênin a dizer que a grande cidade é uma herança do capitalismo, e veio para ficar, devendo os planejadores do futuro levar em conta essa realidade. (SANTOS, 1988, p. 23)

Diamond (2005) afirma que os diferentes ritmos nos avanços da humanidade ocorreram graças às diferenças entre os ambientes e não diferenças biológicas, o que conduz ao pensamento anterior, diferentes ambientes, diferentes culturas e diferentes percepções do tempo colaboram com esta cidade onde se superpõem diferentes momentos históricos, produtivos e religiosos, o que pode colaborar com a preservação do patrimônio cultural.

São percepções do tempo linear e do tempo cíclico que convivem em certas cidades e preservam certas tradições. Um fenômeno bastante comum, ora impulsionado pela manutenção da fé dos sujeitos que compõem a cidade ou pela lógica da produção - a espetacularização organizada pelas políticas de turismo ou as duas coisas ao mesmo tempo.

De qualquer forma assistimos a um esforço para a preservação do patrimônio, pois ele possui significado simbólico para comunidade, é memorável pois faz as pessoas se sintonizarem com a sua identidade e com o sentimento de pertencimento.

\section{AS FESTAS DO DIVINO ESPÍRITO SANTO NO BRASIL E EM MOGI DAS CRUZES}

\subsection{As festas do Divino pelo Brasil}

Aqui, estabelece-se uma ponte entre algumas festas do divino espalhadas pelo território nacional, a fim de que se possa compreender, o segundo questionamento apresentado na introdução deste estudo: ii) que exemplos podem ser citados em que o tempo linear e o tempo cíclico se encaixam na manutenção das festas religiosas e 
consequentemente dos patrimônios culturais?

Afirma Moraes (2003) que as origens da Festa do Divino Espírito Santo estão na Alemanha, na verdade, como toda celebração da religião católica na Europa, muitas festas foram substituindo as celebrações pagãs, assim como a festa do divino, que resultou da adaptação das festas públicas romanas conhecidas como "Florália", em que se celebrava o renascer da vida, justamente na chegada da primavera. Da Alemanha a festa foi levada para Portugal, no século XIV, pelo rei D. Diniz e pela rainha Isabel como uma festa religiosa, devido a uma promessa da rainha, que pediu ao Divino Espírito Santo ajuda para superar crise que o país enfrentava. Ao ver seu pedido atendido, após a superação da crise, promoveu uma grande festa em agradecimento, que se repetiu nos anos seguintes durante o período de Pentecostes, sendo que: "[...] o culto é instituído e, ao longo dos séculos, popularizado em diversas localidades do solo português, com funções caritativas, como, como distribuição de alimentos e soltura de presos, e de invocação contra doenças” (MORAES, 2003, p. 42).

A festa foi trazida para o Brasil pelos portugueses no período colonial, sofrendo várias adaptações e sincretismos devido ao clima, ao folclore indígena e africano, como a Congada, o Moçambique, as Marujadas etc., que foram incorporados ao Catolicismo e se apresentando de formas distintas de acordo com a região em que a festa foi implantada, revelando no particular a dinâmica cultural e social do local.

As festas no Brasil adquiriam características do povo caipira, da população rural. Brandão (1974) afirma que as festas no Brasil central ocorrem sempre no período da colheita dos cereais, entre maio e agosto, já Pires (2009) assevera que as festas em Piracicaba conservaram suas tradições devido ao alto grau de isolamento do povoado.

Uma pesquisa rápida pela literatura acerca das Festas do Divino no Brasil conduzem a símbolos, objetos e práticas que assemelham e que se distanciam. Entre as semelhanças está sempre presente a imagem da Pomba Branca, roupas e adornos vermelhos são também bastante frequentes. Entre os objetos simbólicos estão as coroas, os cetros, a bandeira, os mastros, distribuição de lembrancinhas e de alimentos - normalmente pão e carne, embora surjam doces e outras iguarias. (FRADE, 2005; IZIDORO, 2006; LEAL, 2014). 
Os papéis desempenhados pelos fiéis, também, são bastante representativos: o imperador e a imperatriz, esta última em alguns casos, há, ainda, mordomos, caixeiras, o festeiro e o capitão do mastro, há algumas irmandades - rezadeiras, rezadores, irmãos e irmãs do Divino. Como há sempre muita música nas festas do Divino e muita dança, os músicos aparecem com seus diferentes papéis e diversos instrumentos: tambores, pandeiros, violas e outros instrumentos de corda, são os foliões em alguns casos, e entre esses aparecem o foliõezinhos, ou crianças, cujas vozes mais agudas, destacam-se nas cantorias. (IZIDORO, 2006).

Em algumas festas, particularmente, surgem outros personagens, como em Pirenópolis onde a Cavalhada acontece há mais de 400 anos (BRANDÃO, 1974), os cavaleiros enfeitam seus cavalos e durante três dias se enfrentam num jogo que representa a luta entre cristãos e mouros.

Em outras cidades, o elemento afro é bastante forte com a presença das Congadas, que também evocam as lutas entre mouros e cristãos que se estenderam por um longo tempo na Península Ibérica (PIRES, 2009).

Frade (2005) aponta festas do Divino em Santa Catarina, Minas Gerais, Maranhão, São Paulo, Goiás e Rio de Janeiro. Em Minas Gerais, as festas se destacam em Diamantina e São João Del Rei, ambas se caracterizam, segundo a autora, pela rica indumentária que remete ao ciclo dos minérios que fez ascender a economia mineira.

No Maranhão, há duas vertentes bem diferentes: na cidade de São Luís, as festas trazem o sincretismo religioso, pois elas acontecem nos terreiros em sua grande maioria, e são conhecidas como Tambor de Mina (LEAL, 2014). Já em Alcântara, a festa tem uma adesão à Igreja Católica, porém as personagens principais são as caixeiras, consideradas sacerdotisas que conduzem os rituais da festa do Divino Espírito Santo, cantam e entoam hinos nas alvoradas. Essas mulheres vêm de comunidades quilombolas e passam por um grande aprendizado até chegarem a este posto (GOMES, 2013).

Em São Paulo, há dois tipos de Festa de do Divino: na terra e no rio (Tietê ou Piracicaba), essas últimas acontecem em Piracicaba e Anhembi - cidades vizinhas - e ambas têm características semelhantes, pois os irmãos saem com o barco, ao longo do rio, visitam as casas numa ação conhecida como pousos, onde rezam e cantam 
durante alguns dias - às vezes 9, às vezes 7 - e no seu retorno os barcos se encontram no rio numa festividade acompanhada de muita música, oração e grupos folclóricos (PIRES, 2009).

Das festas que acontecem em terra, no Estado de São Paulo, há a Festa de Mogi das Cruzes, que se estuda a seguir.

\subsection{A festa do Divino em Mogi das Cruzes}

Mogi das Cruzes foi fundada em 1560, mas é só a partir do final do século XIX que o município passa por mudanças paradigmáticas, que podem ser divididas em três fases: a implantação da estrada de ferro; a chegada dos imigrantes e a instalação das universidades.

O primeiro momento, o da chegada da estrada de ferro, iniciou-se em o6 de novembro de 1875, com a inauguração do tráfego entre São Paulo e Mogi das Cruzes pela estrada de ferro do norte, mas nesse momento apenas para o transporte de mercadorias. Segundo Grinberg (1983, p. 25), só em 1911 iniciou-se a circulação dos trens para o transporte de passageiros, sendo que no início "[...] faria correr um trem de subúrbio entre as duas cidades, saindo de Mogi de manhã e regressando de São Paulo à tarde. No ano seguinte passou a correr dois trens diários e depois três". (GRINBERG, 1983, p. 25).

Tal fato possibilitou, pelo menos em parte, a quebra do isolamento da cidade que se constituiu entre duas serras, que, segundo Grinberg (2001), até o início do século XX, sua população tinha grande dificuldade de comunicação e de acesso à capital paulista, trajeto que levava em torno de quatro dias para ser percorrido. Tais aspectos comprometeram o desenvolvimento da cidade, visto que em 1886, Mogi das Cruzes contava com uma população de 19.454 habitantes (GRINBERG, 2001) e uma ocupação territorial urbana tímida, sendo:

O principal centro de Mogi das Cruzes era composto, por volta de 1872, por dezesseis ruas e nove largos, além de algumas travessas. O traçado das ruas obedecia, ainda, ao traçado colonial [...] E este desenho se mantem praticamente inalterado até o começo do século XX (1901), em que se consta a pouca transformação e crescimento urbano em tão longo espaço de tempo (ZAMAI, 2008, p. 26). 
Para a autora o processo de modernização de Mogi das Cruzes está intimamente ligado à história de seus caminhos, iniciando-se com abertura da estrada de ferro, e posteriormente com as rodovias, como a Rodovia Presidente Dutra (BR-116), inaugurada em 1951, e a ligação do município com esta via pela Rodovia Mogi-Dutra, em 1975, que facilitaram o acesso a São Paulo, por um lado, e ao Rio de Janeiro, por outro. Com a inauguração da Rodovia dos Trabalhadores, na década de 80, a atual Rodovia Ayrton Senna, um atual acesso mais rápido à capital paulista e ao Aeroporto Internacional de Cumbica, em Guarulhos, entre outras localidades de referência do ponto de vista econômico, cultural e de lazer.

O segundo momento de intensificação do desenvolvimento foi a partir da imigração, que, segundo Moraes (2010), se deu em consequência da estrada de ferro, que incentivou a vinda de imigrantes ao município, principalmente, neste primeiro momento, italianos, espanhóis, libaneses e sírios, que:

Desejosos de um progresso material que a pátria-mãe não tinha oferecido, estes imigrantes foram buscar novas oportunidades principalmente no comércio local, já que a zona rural não oferecia grandes chances de lucro imediato (MORAES, 2010, p. 106).

Com o aumento do comércio, a cidade ganha uma nova configuração, com a instalação de padarias, bares, lojas de ferragens, de secos e molhados etc., muitos dos quais passaram a ocupar as ruas centrais e forçar a expansão territorial do município, favorecendo a criação de novos bairros, intensificando a modernização da cidade.

Os imigrantes, que começaram a chegar no município no final do século XIX, influenciaram a utilização de novas técnicas construtivas e de organização do espaço urbano. Moraes (2010) afirma que a taipa de pilão e a taipa de mão, técnicas até então utilizadas na construção das edificações no município, foram substituídas pela alvenaria de tijolos, técnica empregada pelos imigrantes nas novas construções de suas moradias e espaços comerciais. Além disso, trouxeram uma série de outras novidades, como:

[...] o calçamento das primeiras ruas, a introdução da iluminação elétrica, o uso do papel de parede nas casas mais abastadas, o gosto pelas porcelanas e cristais, novas instalações sanitárias, fogões de ferro, relógio de parede em forma de oito, entre outros (MORAES, 2010, p. 108). 
Depois deste período, chegaram os japoneses, imigrantes que a partir de 1919 mudam em grande quantidade ao município, tendo, inicialmente, uma grande influência no desenvolvimento da agricultura e da avicultura na cidade.

O terceiro momento que impulsionou o desenvolvimento do município foi com a instalação das universidades, que provocaram grandes mudanças na rotina da cidade, pois a formação profissional que se avizinhava iria trazer melhorias no mercado de trabalho, na distribuição de bens públicos e privados e vagas para trabalhadores.

Assim, uma conclusão a que se chega diante deste quadro é de que o município desenvolveu-se, efetivamente, apenas a partir do final do século XIX século XX. Os séculos que antecederam, visto que o município passou por um longo período um isolamento, o que proporcionou a preservação de alguns patrimônios, como a festa do Divino Espírito Santo, que manteve sua essência religiosa e da cultura popular por séculos, sofrendo alterações mais intensas apenas a partir das últimas décadas do século XX.

Segundo Campos (2013), os primeiros registros que se reportam à Festa do Divino Espírito Santo em Mogi das Cruzes datam do século XVIII, nos "Livros de Gasto e Receita da Ordem Primeira do Carmo”, que descrevem, no período entre 1749 a 1762, o gasto com cera para vela para a realização da festa.

Outro registro importante da festa na cidade foi realizado por Mário de Andrade, que em 1936, em visita ao município, em companhia de Lévi-Strauss e sua esposa, com o intuito de filmar a Festa do Divino Espírito Santo, comenta sobre a Entrada dos Palmitos, procissão que ocorre durante a festa em agradecimento a fartura e a colheita1.

Andrade (1937) destaca a relação da Entrada dos Palmitos com o culto à primavera realizada nas festas pagãs europeias, o que se percebe, segundo o autor, pela tradição de se enfeitar carros de bois com flores e alimentos, Até hoje, este é o momento de maior concentração de fiéis e observadores durante a festa. Andrade, também, comentou sobre as manifestações populares como a Cavalhada, Moçambique e Congada, que acompanham a procissão.

1 O vídeo encontra-se disponível na rede social Youtube, no link: <https:// www.youtube.com/watch? $\mathrm{v}=\mathrm{k} 14 \mathrm{zxJHPIOo}>$. 
Assim, a Festa do Divino Santo de Mogi das Cruzes, com mais de trezentos anos de história (GRINBERG, 1983), foi se constituindo como uma importante manifestação de religiosidade e de cultura popular, compondo o calendário litúrgico da cidade, sendo uma referência para a população, que participa efetivamente das festividades, ou seja, o tempo cíclico se impõe sobre o tempo linear e a celebração se mantém, o que evidencia sua relevância como um patrimônio imaterial para a comunidade local.

Neste ponto, a terceira hipótese deste percurso se apresenta: como pensar em políticas de salvaguarda e preservação de patrimônio cultural que possam deter os efeitos deletérios do nivelamento cultural no cenário da globalização?

Apolloni \& Andrade (2010) afirmam que a redução da visão cíclica da natureza afetou a relação dos seres humanos com a divindade, e as metrópoles tem um papel acelerador nesse conceito.

Com uma história e patrimônios significativos que merecem ser preservados e divulgados, o município passou a estabelecer políticas públicas de proteção aos bens culturais locais, dentro da lógica da UNESCO. Em sintonia com a Constituição Federal de 1988, foi instituída, em 2003, a Lei Municipal 5.500, que criou o Conselho Municipal de Preservação do Patrimônio Histórico, Cultural, Artístico e Paisagístico de Mogi das Cruzes, e em seguida, a Lei 6.086, de 2007, que estabelece normas de preservação do patrimônio cultural material e natural da cidade. No mesmo ano, surgiu o Decreto municipal 7.970, que instituiu o registro dos bens culturais de natureza imaterial. (MOGI DAS CRUZES, 2007).

Segundo estes princípios, algumas manifestações passam a compor o Registro de Bens Culturais de Natureza Imaterial (Livros de Registros dos Saberes, das Celebrações e das Formas de Expressão) de Mogi das Cruzes, entre as quais a Festa do Divino Espírito Santo e alguns patrimônios culturais imateriais presentes na festa, como:

- Afogado: comida típica de carne bovina e temperos, servidos com caldo e farinha de mandioca, comercializada na quermesse e distribuída gratuitamente à população no dia da Entrada dos Palmitos; 
- Congada e o Moçambique: folguedos de formação afro-brasileira, que destacam costumes e tradições de Angola e Congo, manifestações presentes em vários momentos da festa;

- Rezadeiras e Rezadores: grupo de fieis que rezam a Coroa do Divino nas casas e em instituições públicas e privadas a pedido dos fieis e nas alvoradas, procissões matinais que acontecem durante nove, dos dez dias em que acontece a festa;

- Entrada dos Palmitos: também inscrita no Registro de Bens Culturais Imateriais, compondo assim um conjunto de manifestações e saberes que passaram a ser valorizados e protegidos por uma política pública que visa sua preservação.

Mas apenas essas manifestações e saberes não possibilitam o pleno entendimento da abrangência da festa, de sua simbologia, rituais, etc. que constituem um rico conjunto de tradições religiosas e culturais, entre outros aspectos. Neste sentido apresenta-se um dos momentos da festa, na figura 1, a Alvorada.

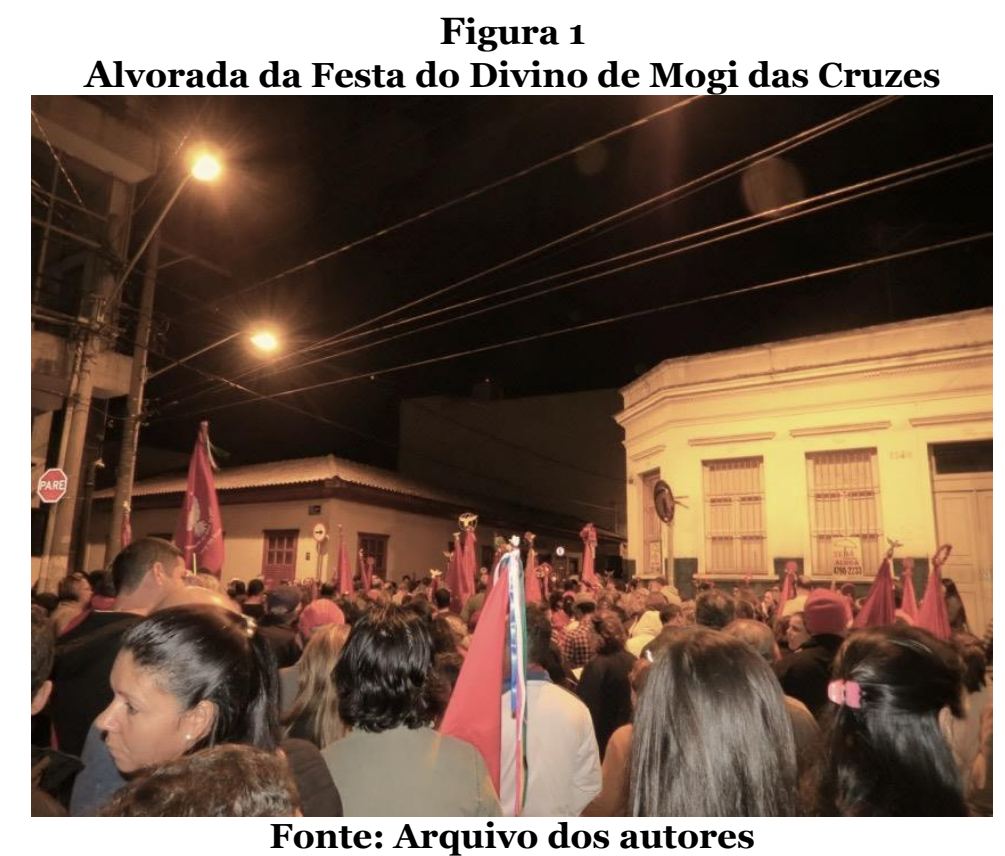

A Alvorada é uma procissão que serpenteia a cidade nos dez dias da festa, tem início às 5 horas da manhã e termina uma hora depois, no salão paroquial da Catedral de Santana. Nos dez dias da festa entre as várias comemorações, as novenas e as 
Alvoradas são as mais representativas para o tempo cíclico, pois são momentos de orações e cânticos, é o tempo do humano religioso.

A procissão caminha pelo centro da cidade, entre construções que marcam o passado e o presente. Prédios mais antigos e outros mais modernos avistam, na escuridão do inverno, a passagem dos fiéis que interrompem o fluxo de trânsito da cidade que amanhece.

Prados (2016, p. 51) afirma que a Alvorada, semioticamente falando, é uma narrativa da vida, pois os fiéis são sujeitos em busca de um objeto de valor: "parte-se de um ponto de origem e caminha-se sem saber, ao lado de pessoas conhecidas e desconhecidas, mas adjuvantes nessa busca pela Fé”. (PRADOS, 2016, p. 51).

A mesma autora afirma que caminha-se em direção ao nascer do sol, metáfora da luz que conduz à paz.

Concluídos os esforços da caminhada matinal, os fiéis se dirigem ao moderno Salão Paroquial, construído com essa finalidade, muito recentemente, figura 2. Lá é servido o café da manhã, tradicional conjunto de café preto ou chocolate quente, pão com mortadela e biscoitos, essa tradição já se constitui há mais de 40 anos.

\section{Figura 2}

\section{Café da manhã após as alvoradas da festa do divino de Mogi das Cruzes}

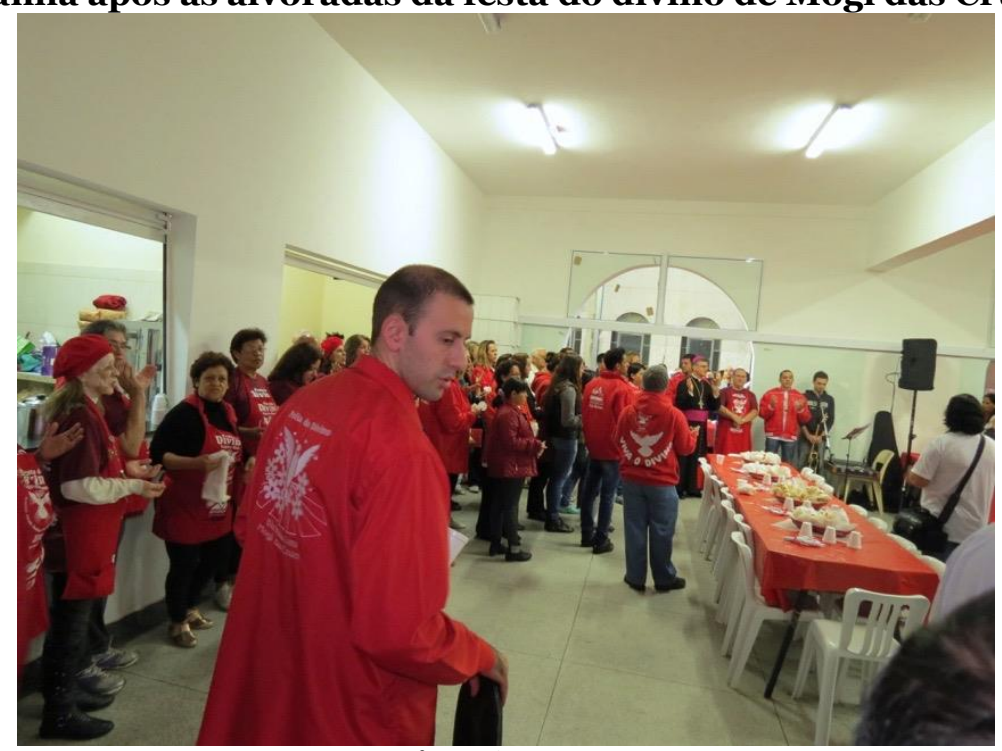

Fonte: Arquivo dos autores

Para Bonini \& Melo (2013): "O alimento é resultado de uma conquista, após o trabalho: ganhar o pão.” No caso, o trabalho foi a procissão. Ao madrugar, o devoto trabalha fazendo seus pedidos e orando, agradando, assim o Divino Espírito Santo a 
terceira pessoa da Trindade.

Nesses momentos da festa, é que se distingue o ser humano religioso do ser humano não-religioso, o primeiro vive em dois planos: sua existência mesma e a esperança da vida transcendental e o tempo sagrado é circular; já o segundo dessacralizou o mundo, relativizando-o, é o humano histórico cujo tempo é linear. (QUEIROZ e NUNES, 2014). É na visão do tempo cósmico, repetível indefinidamente que o humano religioso conseguiu manter as tradições vivas, despertando um olhar mais acurado dos promotores de políticas culturais e de turismo que pudessem, mesmo com interesses capitalistas, buscar conservar, preservar e salvaguardar essas tradições.

\section{CONSIDERAÇÕES FINAIS}

Ao encerrar este texto observa-se que ao refletir sobre o tempo cíclico que mantém as festas populares presentes em todo território brasileiro, foi possível compreender que mesmo na globalização, mesmo num sistema produtivo e consumista que preza o tempo linear, as festas e celebrações se mantiveram e se resguardaram em grande parte na sua essência.

Grande parte dessas festas atualmente integram os calendários turísticos dos municípios e a gestão pública entendeu que, ao garantir legalmente essa preservação, estavam preservando espaços de produção, não só sazonalmente, para as datas das festas, mas ao longo do ano todo, preenchendo espaços, museus, ações isoladas para atrair turistas, e claro vem atraindo a mídia que espetaculariza muitas dessas ações em nível local, já que tem patrocínio certo, e às vezes, mesmo regionalmente, se vê reverberações dada a magnitude do evento.

A problemática que moveu este estudo parece respondida, ainda de modo breve, mas entendeu-se que a cidade resguarda seus diferentes momentos, suas diferentes produções, mesmo com o avanço da economia, com o enfraquecimento das tradições, essas acabam triunfando sobre a gestão das políticas culturais e se transformam em fênix renascidas por meio do esforço daqueles que buscaram manter seus aspectos. Exemplos nestes casos não faltaram, principalmente em relação à Festa do Divino Espírito Santo no Brasil. 
Não é fácil escolher o que vai ser levado em consideração nas políticas de salvaguarda de bens culturais, mas um fenômeno vasto como a Festa do Divino deixa um exemplo bem claro da extensão das preocupações que impulsionaram recentemente os processos de gestão dessas políticas de salvaguarda e conservação em vários estados do país.

Ao pesquisar a Festa do Divino em Mogi das Cruzes constatou-se que boa parte de sua essência permaneceu sem grandes alterações até meados dos anos de 1970, período em que a cidade passou a conviver com um crescimento populacional, profissional, logo abrindo as portas para o mundo globalizado e mais economicamente impulsionado, devido às universidades que se instalaram na região, com os melhoramentos dos canais de comunicação e transporte tais como rodovias que facilitaram o acesso do município a São Paulo, Rio de Janeiro e ao litoral norte, que facilita a chegada ao porto de Santos.

O isolamento territorial, o cerco entre a Serra do Mar e a Serra do Itapety, que dificultava a circulação das pessoas e de mercadorias, inibiu o crescimento do município, fatores que favoreceram a permanência da Festa do Divino, dos rituais e a simbologia que a envolvia por um longo período.

Porém, por um lado, com a expansão da cidade, algumas alterações nos rituais religiosos e da cultura popular que permeiam a festa foram surgindo, principalmente nos momentos e espaços que recebem um número maior de pessoas, que passaram a sofrer a influência do mundo globalizado, da sociedade do espetáculo, se constituindo em grandes eventos e com distorções que gradativamente se afastam de sua configuração inicial. Por outro lado, na dimensão religiosa nota-se que a essência da festa, mesmo com novas configurações que foram se estabelecendo durante os anos, a Festa do Divino de Mogi das Cruzes mantém seus símbolos, rituais e fazeres, presentes nas procissões, nas Alvoradas e nas novenas, que envolvem os devotos, o sujeito religioso, cujo tempo é circular e cuja presença é fundamental na preservação do sentido da festa. 


\section{REFERÊNCIAS}

ANDRADE, Mário. A entrada dos palmitos. Revista do Arquivo Municipal, São Paulo, v. 32. p. 51-64, 1937.

APOLLONI, Rodrigo W.; ANDRADE, Joachim. A metrópole e o futuro da religião. Interações - Cultura e Comunidade, Uberlândia, v.5, n. 8. p. 79-96. jul./dez. 2010.

BONINI, Luci M.M.; MELO, Eliana M. Festa do Divino em Mogi das Cruzes: o percurso da fé e a conquista do alimento santificado. Anais do $9^{\mathbf{0}}$. Encontro internacional de Música e Mídia. 18 a 20 de Setembro de 2013. Disponível em: $<$ http://musimid.mus.br/9encontro/wpcontent/uploads/2013/11/9musimid_bonini-melo.pdf.>. Acesso em: 02 mar. 2017.

BRANDÃO, Carlos R. Cavalhadas de Pirenópolis: um estudo sobre a representação de cristãos e mouros em Goiás. Goiânia: Oriente, 1974.

CAMPOS, Jurandir F. de. (Org.). A Festa do Divino em Mogi das Cruzes: quatrocentos anos de devoção - aspectos históricos e iconográficos. Mogi das Cruzes: Associação Pró-Festa do Divino Espírito Santo, 2013.

CLAVAL, Paul. A festa religiosa. Ateliê Geográfico, Goiânia, v. 8. n. 1, p. 06-29. Abr. 2014. Disponível em: <https://www.revistas.ufg.br/atelie/article/viewFile/29952/16526>. Acesso em: 13 mar. 2017.

CORRÊA, Aureanice de M. Espacialidades do sagrado - a disputa pelo sentido do ato de festejar da Boa Morte e a semiografia do território encarnador da prática cultural afro-brasileira. In. SERPA, Angelo. Espaços Culturais: vivencias, imaginações e representações. Salvador: EDUFBA, 2008. p. 161-179.

DIAMOND, Jared. Armas, Germes e aço: os destinos das sociedades humanas. São Paulo: Record, 2005.

ELIADE, Mircea. El mito del eterno retorno. 1. ed. Buenos Aires: Emecé, 2001.

FRADE, Cáscia. Festas do Divino no Brasil. Textos escolhidos de Cultura e Arte populares. vol. 2, no. 2, 2005. Disponível em: <http://www.epublicacoes.uerj.br/index.php/fecap/article/view/12634>. Acesso em: 27 fev. 2017.

GRINBERG, Isaac. Folclore de Mogi das Cruzes. São Paulo: I. Grinberg, 1983. GRINBERG, Isaac. Memória fotográfica de Mogi das Cruzes. São Paulo: Ex Libris, 2001. 
GOMES, Cristine M. Turismo e cultura no Maranhão: as caixeiras da Festa do divino Espírito Santo em Alcântara. Dissertação de mestrado profissional em Gestão de Negócios Turísticos. Fortaleza: UECE, 2013.

GORGULHO, Guilherme. Lévi-Strauss e Mário de Andrade em Mogi das Cruzes - 1936 (vídeo). Disponível em:

<https://www.youtube.com/watch?v=k14zXJHPIoo>. Acesso em: 26 fev. 2017.

IZIDORO, José L. A religiosidade popular na cultura caiçara: a Festa do Divino Espírito Santo em Iguape. Anthropos. Bd. 101, H1. 2016. p. 169-178.

LEAL, João. Festa maior dos terreiros: Divino e Mina em São Luís (Maranhão).

Revista Pós Ci. Soc. v.11, n. 21, jan./jun. 2014. Disponível em:

$<$ http://www.periodicoseletronicos.ufma.br/index.php/rpcsoc/article/view/2871>. Acesso em: 06 mar. 2017.

LE GOFF, Jacques. El ordem de la memoria: el tiempo como imaginário. Buenos Aires: Ediciones Paidos, 1982.

MOGI DAS CRUZES. Decreto no 7970, de 10 de setembro de 2007. Edital no 44, de 28 de Dezembro de 2009. Mogi das Cruzes. Disponível em:

<http://www.comphap.pmmc.com.br/arquivos/44_2009.pdf. >. Acesso em 26 fev. 2017.

MOGI DAS CRUZES. Lei municipal 5.50o, de 30 de Maio de 2003. Disponível em:

<http://www.comphap.pmmc.com.br/arquivos/lei_municipal/5500_2003.pdf.>. Acesso em: 28 fev. 2017.

MOGI DAS CRUZES. Lei municipal 6.o86, de 18 de dezembro de 2007.

Disponível em:

<http://www.comphap.pmmc.com.br/arquivos/lei_municipal/6086_2007.pdf.>. Acesso em: 28 fev. 2017.

MORAES, Fernando O. A festa do divino em Mogi das Cruzes: folclore e massificação na sociedade contemporânea. São Paulo: Annablume, 2003.

MORAES, M. S. Nova História de Mogi das Cruzes. 1. ed. Mogi das Cruzes: Editora Mogi News, 2010. v. 4000. 335 p .

QUEIROZ, Rodrigo D.; NUNES, Antônio V.. A experiência do tempo no sagrado e no profano à luz da interpretação de Mircea Eliade. Revista de Filosofia

Aufklarung. v. 1, n. 2, out. 2014.

PIRES, Cibelia. R.S. A religiosidade caipira: a festa do Divino em Piracicaba. Fênix Revista de História e Estudos culturais, Uberlândia, v. 6, ano 6, n. 2, abr./mai./jun. 2009. Disponível em: <http://www.revistafenix.pro.br >. Acesso em 26 fev. 2017. 
PRADOS, Rosália M. N. A alvorada: signos e significação. In. BONINI, Luci M. M.; PEREIRA, Rute P.F. Rezadeiras e Rezadores na Festa do Divino Espírito Santo de Mogi das Cruzes, SP: os saberes e fazeres como patrimônio cultural. São Paulo: Editae, 2015. p. 49-52.

SANTOS, Milton. Metamorfoses do Espaço Habitado: fundamentos Teórico e metodológico da geografia. São Paulo: Hucitec, 1988.

ZAMAI, Silvia B. Valorização do patrimônio cultural de Mogi das Cruzes. 2008. 159 f. Dissertação (Mestrado em Arquitetura e urbanismo) - Universidade Presbiteriana Mackenzie, São Paulo, 2008. 